SECCIÓN ABIERTA 

REVISTA DE DERECHO UNED, NÚM. 10, 2012

\title{
A PROPÓSITO DE LOS FUNDAMENTOS DE DERECHO ROMANO DEL PROFESOR DR. ANTONIO FERNÁNDEZ DE BUJÁN
}

\author{
Alfonso Agudo RuIZ \\ Catedrático de Derecho Romano \\ Universidad de La Rioja
}

En 1996, después de veinte años en la docencia del Derecho Romano, vio la luz la primera edición del Derecho Público Romano del Prof. Dr. Antonio FERNÁNDEZ DE BUJÁN, Catedrático de Derecho Romano de la Universidad Autónoma de Madrid. Como dejo escrito el A. en el Prólogo de su obra «las páginas que siguen están destinadas a los estudiantes, verdadera razón de ser de la institución universitaria..., nacen, ante todo, con el deseo de contribuir a la afición por el estudio y a la vocación por la ciencia de las sucesivas promociones de alumnos universitarios». Aquél deseo se ha visto cumplido sobradamente, pues en un breve lapso de tiempo, 16 años, se han realizado 15 ediciones, que han permitido a su A. adicionar en cada nueva edición nuevos capítulos fruto de los resultados de sus investigaciones o de las que ha dirigido, siempre en el convencimiento «de que el ámbito del saber histórico no debe configurarse como un sistema cerrado, sino como una parcela del proceso científico, siempre abierto y en constante desarrollo». Estamos pues ante un manual ya clásico en nuestra disciplina, donde el A. ha conseguido aunar magistralmente la difícil dualidad de su finalidad pedagógica, merced a una impecable estructura lógica, orden expositivo y al uso intencionado de un lenguaje claro y sencillo, que convierte al manual en accesible a los alumnos, con su finalidad científica, donde el A. nos ofrece sus profundas conclusiones personales fruto de su elevado grado de madurez profesional y de su incesante labor investigadora, completado cada uno de los temas con una cuidada, selecta y actua- 
lizada bibliografía, que lo hace referente obligado para cualquier investigación romanística.

La actividad manualística de mi maestro se verá completada en el año 2008 con la publicación de su primera edición del Derecho Privado Romano, donde aborda el estudio del derecho de la persona, el derecho de familia, el negocio jurídico y los derechos reales. Al igual que sucediera con su Derecho Público Romano, la gran aceptación por el amplio sector de lectores al que va destinada, ha propiciado que en 2011 haya visto la luz la $4^{a}$ edición. Durante este tiempo, el Manual ha ido creciendo en contenido en las sucesivas ediciones, así en la $3^{\mathrm{a}}$ el A. adiciona la parte correspondiente al derecho procesal, objeto de tratamiento en el precitado Derecho Público Romano, completado cada uno de los temas con una cuidada, selecta y actualizada bibliografía y un exhaustivo índice analítico que facilita el estudio del manual, en la $4^{\mathrm{a}}$ incorpora la parte correspondiente al derecho de obligaciones, así como la correspondiente actualización bibliográfica de cada uno de los temas. La materia se expone con absoluto rigor científico, claro y sencillo, en un discurso elegante, lleno de agudísimos matices y sugerencias innovadoras, como corresponde al reconocido magisterio de su A., entre la que destaca la labor de conexión entre el Derecho Romano y el ordenamiento jurídico civil vigente, poniendo así de relieve como escribe el A. en la contraportada «que un número importante de artículos de este cuerpo legal, paradigma legislativo, constituyen el último eslabón de la evolución del pensamiento jurídico desde Roma hasta el actual derecho positivo».

En 2011, ha visto la luz la primera edición de la obra que tenemos el honor de reseñar «Fundamentos de Derecho Romano», publicada por el Centro de Estudios Financieros, dirigida a los alumnos del Grado en Derecho de la Universidad a Distancia de Madrid. La obra, conformada por el Derecho Público Romano y el Derecho Privado Romano, suponía un nuevo reto para su A. por dos motivos, en primer lugar, el nuevo marco jurídico en el que se ubican los actuales estudios de Derecho, el denominado Espacio Europeo de Educación Superior, regulado por el Real Decreto 1393/2007, que como afirma el A. en el Prólogo «ha supuesto una reducción sustancial de la parte teórica dedicada a las disciplinas jurídicas en los nuevos planes de estudio»; en segundo lugar, la especificidad de las enseñanzas a distancia donde el alumno es el protagonista activo de su propio proceso de aprendizaje y donde el manual adquiere un valor especial por cuanto que, en cierta medida, debe cumplir la misión formativa asignada tradicionalmente a la clase teórica. Ambos retos han sido lo- 
grados con magistral éxito. Capacidad de síntesis y claridad expositiva, virtudes poco comunes en la generalidad manualística, constituyen el signo de identidad de «Fundamentos».

El A. presenta de manera inmejorable las ideas fundamentales para la enseñanza, resultado de sus sólidas investigaciones. La materia se expone con absoluto rigor científico, de modo claro y sencillo, en un discurso elegante, lleno de agudísimos matices y sugerencias innovadoras, como corresponde al reconocido magisterio de su A. Abundan las referencias a las fuentes romanas, jurídicas y literarias, prescindiendo conscientemente de estériles polémicas doctrinales y de citas a pie de página, que en algunos casos abruman más que iluminan, con una cuidada y selecta bibliografía al final de cada Unidad, que nos pone claramente de relieve que el A. ha tenido muy en cuenta los estudios recientemente publicados, cuyos resultados han sido objeto de algunas precisiones críticas. Destacar, como hace el A. en el Prólogo, la colaboración de la Doctora Escutia, autora de los apartados denominados: conceptos básicos a retener, actividades de autocomprobación, ejercicios voluntarios y el glosario de términos latinos.

Es digno de especial consideración las continuas referencias que a lo largo de la obra dedica el A. al Código Civil, lo que sin duda contribuye a crear en el ánimo de los jóvenes estudiantes el sentimiento de necesidad de estudio del Derecho Romano para un recto conocimiento de nuestro Ordenamiento jurídico. En este orden de ideas nos permitimos reproducir los párrafos $4^{\circ}$ y $5^{\circ}$ del Prólogo: «La experiencia iusprivatística romana constituye una manifestación clásica de la ciencia del Derecho, que trasciende el período de tiempo en que se produce para conformar el pilar básico sobre el que se asienta el Derecho privado continental europeo. La mayoría de los conceptos, instituciones, reglas y soluciones a las cuestiones, así como la sistemática que informa el actual ordenamiento jurídico, en materia de Derecho privado, tienen su origen en el Derecho Romano. Roma inventa el Derecho en Occidente, y ensambla por vez primera, en expresión orteguiana, el oriente y el occidente de Europa. El estudio del Derecho privado romano constituye no sólo un elemento indispensable para valorar la historicidad del Derecho, sino que también se configura como un instrumento necesario para entender el Derecho vigente y para ayudar a la construcción del Derecho privado de la Unión Europea, que el irreversible proceso unificador nos deparará en el futuro, sobre los elementos comunes que el Derecho Romano proporciona a los Códigos civiles europeos. En este sentido, conecta en numerosas instituciones el Derecho Romano con el vigente Códi- 
go Civil español, a fin de dejar constancia de que un número importante de artículos de este cuerpo legal, paradigma legislativo, constituyen el último eslabón de la evolución del pensamiento jurídico desde Roma hasta el actual Derecho positivo».

Cabe, por todo lo expuesto afirmar que la obra del Prof. Fernández de Buján va más allá del ámbito docente al que, en principio se dirige, y resultará de interés asimismo a los romanístas y, en general, a la comunidad jurídica.

La sistemática adoptada responde a la tradición pandectística, aunque con algunas importantes novedades. De la exposición en su conjunto, voy a destacar aquellos aspectos que me parecen especialmente significativos.

La Unidad didáctica 1 (págs. 9-46) titulada Breve historia del Derecho Romano, se inicia clarificando el concepto de Derecho Romano, seguido de las distintas etapas que conoció Roma a lo largo de sus XIV siglos de vida. Muy acertado nos parece el apartado titulado «El Derecho Romano como elemento esencial del Derecho europeo», pues muestra a los jóvenes alumnos que el Derecho europeo no surge por generación espontánea en la mitad del siglo pasado, sino que hunde sus raíces en Roma, en palabras del A. «conceptos fundamentales del Derecho constitucional romano han influido en la configuración del Derecho público europeo y del Estado moderno, y el Derecho bizantino romano constituye el fundamento de las legislaciones de las naciones del este europeo».

A través de las noticias suministradas por la tradición histórica, cuestionada sin razón por las modernas investigaciones, resalta el A. la relevancia de la agrupación de diversas familias o gentes y del vínculo religioso en el nacimiento de la primitiva ciudad-estado. Destaca la concepción patriarcalista de la originaria familia basada en la agnación, así como su carácter de organización política semejante al Estado o comunidad política.

En relación con el rey, sostiene el A. que el primitivo rey tendría una naturaleza carismática y religiosa. Sus poderes no habrían sido delimitados de manera precisa, sino que habrían ido oscilando en función del peso de las diversas instituciones en cada etapa, y con un mayor protagonismo en el período de gobierno etrusco. Rechaza el A. que la Monarquía haya tenido carácter hereditario-familiar ni adoptivo ni electivo. En la designación de cada rey habrían tenido un papel fundamental el Senado y los augures. A continuación se afronta la 
cuestión de la organización sacerdotal y de las competencias de los diferentes colegios: pontífices, augures, vestales y flamines.

En relación con el Senado, acepta el A. la tradición que atribuye su creación a Rómulo, órgano de la aristocracia patricia, destaca su composición por los más influyentes, los jefes de las familias o de las gentes. Sus funciones en la etapa monárquica serían el interregnum y el asesoramiento al rey.

Los comicios curiados nacen con un carácter no ya étnico, sino territorial del que formarían parte todos los ciudadanos romanos varones, patricios y plebeyos, a la que asigna funciones sociales y religiosas. Acepta la tradición que atribuye a Servio Tulio la creación de los comicios por centurias como una organización esencialmente militar, en sustitución del viejo ejército gentilicio, sobre la base de la falange hoplítica. Supone un paso más en el proceso de equiparación entre patriciado y plebe, por cuanto que el criterio de adscripción de los ciudadanos a una u otra centuria era timocrático, en los orígenes, según pudiesen costearse la correspondiente armadura y, con posterioridad, la valoración de su propiedad fundiaria, sobre la base de la unidad de medida de la centuria, conforme a los datos que constasen en el censo, hasta la reforma realizada por el censor Apio Claudio en el 312 a.C., conforme a la que comenzó a valorarse en dinero amonedado.

Aborda el A. el conflicto social entre los dos órdenes del patriciado y de la plebe. El origen de la contraposición se remonta al regnum, si bien ese estado latente cesará con el cambio constitucional adquiriendo su máxima virulencia hasta la mitad del siglo $\mathrm{V}$ a.C. Las reivindicaciones plebeyas se centran en los ámbitos político, social, económico y jurídico, encontrando respuesta a lo largo del siglo IV a.C.

Analiza el A. la estructura constitucional de la res publica, que tanta admiración causó a Polibio, fundada sobre la interacción entre magistraturas, senado y asambleas populares. Destaca el A. la percepción de los romanos hacia la res publica, basada en la ley pública, entendida como producto de la voluntad mayoritaria del pueblo, y la idea de libertas entendida como sometimiento voluntario a la ley votada en común.

Seguido se afronta el examen pormenorizado de las magistraturas en particular: cónsul, pretor, dictador, cuestor, censor, tribuno de la plebe, edil curul y edil plebeyo.

En relación con el Senado republicano, se destaca la primacía del Senado como titular de la potestas de gobierno de la res publica, 
en cuanto que políticamente es expresión de la nueva nobilitas patricio-plebeya y técnicamente tiene un carácter permanente. Asimismo, la singular relación entre el titular del imperium y el Senado se justifica en opinión del A., por una parte, en la lex Ovinia del año 312 a.C. que confiere a los censores la lectio senatus entre personas que han desempeñado las magistraturas y, por otra parte, en la auctoritas senatorial.

Analiza el A. el tratamiento de las asambleas populares, que se inicia con la descripción de la composición de los comicios centuriados, para analizar seguidamente el distinto valor del voto en función de la centuria del votante, consecuencia de la participación directa de todos los ciudadanos en la actividad política. Sigue el examen del procedimiento y competencias de los comicios centuriados. Se cierra el apartado con la exposición de los comicios por tribus.

A continuación, el A. analiza los profundos cambios que la expansión territorial ocasiona en las estructuras institucionales republicanas. Describe la evolución de la acumulación de los poderes de Octavio. Destaca su preocupación por encajar su gobierno dentro de los esquemas republicanos, pues el Senado y las Asambleas son quienes le conceden sus poderes extraordinarios, alejando de sí la imagen del dictator. No obstante, institucionalizó la desaparición de la democracia republicana y relegó definitivamente a las asambleas populares que dejan de reunirse en el curso del siglo I d.C. Aborda el problema de su sucesión. Por último, analiza la administración imperial y provincial surgida del Principado.

En el Dominado o Imperio absoluto se analiza la nueva fórmula política de la tetrarquía establecida por Diocleciano, que responde a exigencias militares y garantiza el orden sucesorio. Interesante son los elementos jurídico-políticos del Bajo Imperio con los que los monarcas de la Edad Moderna construyen el Estado absoluto.

Seguido aborda la relación cristianismo, Derecho Romano y Derecho de la iglesia, donde analiza el impacto político de la muerte de Jesús y las causas de la difusión del cristianismo. La persecución contra los cristianos constituye un aspecto más del absolutismo que Diocleciano imprime a su gobierno. Sigue la tolerancia del primer emperador cristiano favorable a la universalidad de la Iglesia Católica. Constantino establece la exoneración de los munera para los clérigos y recomienda a sus súbditos la adopción del cristianismo con arreglo al credo establecido por el Concilio de Nicea. Finaliza el apartado destacando la influencia del cristianismo en determinadas instituciones. El clérigo adquiere jurídicamente un status privilegiado. 
Se reconoce a los obispos poderes administrativos y jurisdiccionales en asuntos que afectan no solo a clérigos sino también a seglares episcopalis audientia-.

Se cierra la Unidad con el apartado dedicado al Imperio bizantino y a su protagonista Justiniano, que se siente heredero de la grandeza y de la gloria del Imperio romano y aspira a su unidad política-territorial, legislativa y religiosa.

La Unidad didáctica 2 (págs. 47-78) titulada Fuentes del Derecho Romano y dicotomías del ius, se inicia con el estudio de las XII Tablas, su significación política y su contenido. Servirá de base al edicto del pretor y a las posteriores obras de Derecho civil. Su publicación a mediados del siglo V a.C. supone la introducción en el mundo jurídico de principios actuales como la publicidad, certeza, objetividad, seguridad jurídica e igualdad ante la ley. Destaca el A. que la publicación de las XII Tablas no debió implicar un inmediato cambio de la situación preeminente del Colegio de los Pontífices, puesto que el saber laico todavía no se encontraba en un nivel suficiente como para poder interpretar y aplicar de manera continua y regular las disposiciones decemvirales.

Analiza a continuación el A. el Derecho en la época republicana, abordando en primer lugar la jurisprudencia pontifical, depositarios de la tradición, conocedores de los ritos y formularios negociales y procesales, del calendario judicial en el que se distinguía entre dies fasti y nefasti y de la escritura. Destaca que la interpretación del Derecho no se entendía realizada por los pontífices en atención a la voluntad de los dioses, sino que tenía sus propias técnicas, su propia lógica y su propia fundamentación conservadas por escrito y en secreto en los libri pontificales. Distintos hitos acaecidos a partir del siglo V a.C. irán resquebrajando la posición de monopolio del Colegio Pontifical.

El nacimiento de la jurisprudencia laica se sitúa entre los siglos IV y III a.C. y será monopolizada por la nueva clase dominante, la nobilitas patricio-plebeya. Su actividad se concreta en las siguientes funciones: respondere, cavere y agere. La primera alude a las respuestas dadas a dudas planteadas por particulares, magistrados y jueces, es la actividad más importante y constituye el tronco del derecho republicano. La segunda alude al asesoramiento privado en los negocios jurídicos. La tercera alude al asesoramiento en el proceso civil. Destaca la gratuidad de las consultas y de la enseñanza del Derecho. 
Seguido aborda el estudio del derecho honorario y su protagonista, el pretor, magistrado mayor dotado de imperium y de rango casi igual al cónsul. El pretor no tenía potestad para crear o modificar el derecho civil existente. Originariamente, su labor jurisdiccional se reducía a conceder o denegar la acción solicitada. Posteriormente, se le reconoce competencia para interpretar y adaptar el ius civile a situaciones no previstas en la legislación, lo que en la práctica resulta creadora de Derecho, configurando un sistema de protección ágil, flexible, no formalista y en estrecho contacto con la realidad social. Se destacan las razones comerciales como causa de la creación del pretor peregrino, en el 242 a.C., igualmente la nueva realidad económica dará lugar a la creación de un derecho comercial romano que el pensamiento jurídico y filosófico posterior definirá como ius gentium.

A continuación, el A. analiza el concepto de ley: ley como acuerdo y ley como imposición. Destaca como la lex Hortensia, en el 286 a.C., declaró la obligatoriedad de los plebiscitos para todo el pueblo romano, lo que supuso la equiparación de los plebiscitos a las leyes. Recoge distintas clasificaciones de leyes, así la atribuida a Ulpiano: leyes perfectas, leyes menos que perfectas y leyes imperfectas; igualmente, leges rogatae, leges datae y leges dictae. Cierra el apartado con los senadoconsultos.

Analiza a continuación el A. el Derecho en el Principado, comenzando con el análisis detallado de la actividad legislativa del Príncipe formalmente reconocida a partir del siglo II: edictos, mandatos, decretos y epístolas y rescriptos. Destaca la importancia político-legislativa del Senado durante el Principado en detrimento de las asambleas. Durante los primeros príncipes se sigue manteniendo la tradición republicana de que sea el magistrado competente quien solicite la opinión del órgano constitucional. El siguiente paso será el reconocimiento del carácter normativo del senadoconsulto y la presentación del proyecto por el propio Príncipe, oratio principis, que el Senado aprueba sin discusión, como consecuencia del autoritarismo del sistema de gobierno.

La jurisprudencia clásica como fuente de producción del Derecho en el nuevo régimen político es analizada a continuación. El A. acepta la noticia transmitida por Pomponio que atribuye a Augusto la concesión a ciertos juristas, elegidos personalmente por él, del llamado ius publice respondendi ex auctoritate principis, lo que es interpretado por el A. como un control político sobre la jurisprudencia. Destaca el debate doctrinal sobre la finalidad de su concesión como el alcance o grado de obligatoriedad de las respuestas. Describe el 
origen de los juristas del siglo I que en su mayoría proceden del estamento de la nobleza senatorial, mientras que los del siglo II proceden del orden equestre y del mundo provincial. Analiza las dos grandes Escuelas de derecho, la de los Sabinianos y la de los Proculeyanos, que extienden su actividad desde Augusto hasta Adriano. En cuanto a las diferencias entre ambas, considera el A. que los Sabinianos fueron más tradicionales y cercanos al poder político, mientras que los Proculeyanos serían más independientes de la cancillería y su actuación jurídica más innovadora. Seguido, menciona a los juristas que pertenecieron a una y a otra escuela y sus aportaciones más destacables.

El derecho en la época postclásica se abre con el apartado iura et leges, para el A. las constituciones imperiales emanadas del emperador, que reciben el nombre de leges, constituyen la única fuente viva del derecho. Las obras de la jurisprudencia clásica reciben el nombre de ius o iura. A poner fin a la confusión generada ante los tribunales por la invocación por las partes del derecho aplicable, se dirige la Ley de Citas de Teodosio II y Valentiniano III, del 426, en virtud de la cual se disciplina y prioriza el uso de los escritos jurisprudenciales, en el caso de que sean aducidos ante los tribunales de justicia. En Oriente, por el contrario, se publica la primera compilación oficial de las constituciones imperiales en el año 438, casi mil años después de la ley de las XII Tablas, por el emperador Teodosio.

Se cierra la Unidad con el apartado dedicado a la compilación justinianea, considerada como la más importante recopilación jurídica de la historia de la humanidad. Con gran atención es estudiada cada una de las partes que la componen: Código vetus, Digesto, Instituciones, Código nuevo y Novelas. A continuación examina el derecho bizantino postjustinianeo donde se destaca que, a pesar de la prohibición de Justiniano de realizar comentarios a su obra, fueron frecuentes las glosas y compilaciones.

La Unidad didáctica 3 (págs. 79-110) titulada Recepción del Derecho Romano en Europa, se inicia con la recepción del Derecho Romano en Europa, se aborda ampliamente el llamado renacimiento jurídico que se inicia en Bolonia, en el siglo XI, cuando Irnerio estudia y enseña el Digesto a sus alumnos, los cuales realizan aclaraciones o explicaciones de los textos, bien al margen o bien entre líneas del propio párrafo, de ahí la denominación de glosadores. Los siglos XIII y XIV son los del mos Italicus; mientras que los siglos XV y XVI son los del Humanismo y mos Gallicus. Se estudia además el pensamiento racionalista de los siglos XVII y XVIII; las dos grandes codi- 
ficaciones europeas: el Código Civil francés de 1804 y el Código Civil alemán de 1990. Por último, aborda el estudio de la recepción del Derecho Romano en España, Inglaterra y Alemania, así como el Derecho comunitario europeo.

La Unidad didáctica 4 (págs. 111-151) titulada Personas físicas y personas jurídicas. Negocio jurídico. Comienza el A. analizando los términos persona, capax, caput y status. El primero se utiliza para designar al ser humano, con independencia de su condición de libre o esclavo. Con el término capax se alude a la idoneidad de una persona para ser titular de derechos y obligaciones en relaciones concretas. El término caput aparece en las fuentes clásicas referido a individuo integrado en un grupo o comunidad, y de ahí la utilización de la expresión capitis deminutio, para referirse a la salida de una persona del cuerpo orgánico del que formaba parte, o bien para aludir a su cambio de posición jurídica dentro del grupo familiar. Con el término status se hace referencia a la posición de una persona en relación con la libertad -status libertatis-, con la ciudadanía -status civitatis-, o con la familia -status familiae-.

Analiza a continuación el A. los requisitos exigibles previos a la existencia de la persona: nacer con vida, poseer forma humana, y necesidad de que el nuevo ser se encuentre desprendido del seno materno, requisitos que han pasado a las legislaciones modernas. En el natural devenir de la vida, sigue el estudio del fallecimiento, premoriencia y conmoriencia, y la ausencia.

Seguido analiza las causas modificativas de la capacidad jurídica, que son restricciones en la titularidad de determinados derechos por parte de las personas afectadas, basadas en razones o condicionantes de orden político, social o cultural, propios de cada una de las comunidades políticas que han ido desapareciendo de forma progresiva. La primera causa es la condición de mujer, frente a la alta consideración personal y social, no hay correspondencia en la esfera del derecho privado y mucho menos en la del derecho público. Ello obedece a la concepción patriarcalista de la familia, que progresivamente se irá debilitando en las épocas postclásica y justinianea, desaparecida la tutela de las mujeres y el matrimonio cum manu, es decir, aquél caracterizado por el sometimiento de la mujer a la potestad, manus, del marido, se reconoce a la mujer una amplísima capacidad negocial y, en general, se produce un reforzamiento de su capacidad de obrar.

La segunda causa modificativa es la infamia. En opinión del A., la ignominia, que se compone del prefijo negativo ig y de nomen, haría referencia a la privación del buen nombre. La palabra infamia, que 
viene de la raíz misma del verbo fari, se referiría a la mala opinión o mala reputación, la cual en determinados supuestos sería jurídicamente relevante. En los primeros tiempos, la apreciación y, en su caso, sanción dependería de la valoración discrecional del magistrado y, quizás también, del control por la propia familia y por la gens, más tarde por el censor y, por último, por el pretor, en cuyo edicto se contendría un elenco de personas a las que se prohibía actuar como abogado, nombrar representante procesal solemne o procurador o actuar en juicio con esta consideración.

La tercera causa modificativa es la religión. En la República, la esfera religiosa de la persona no produjo modificaciones en su capacidad jurídica. A partir de Nerón se inician las persecuciones a los cristianos que se prolongarán hasta el siglo IV. Con Teodosio I los no cristianos ortodoxos verán limitada su capacidad jurídica.

La cuarta causa modificativa es la condición social, política o profesional. En el orden social, hasta la ley Canuleia del 450 a.C., la condición de plebeyo supuso una limitación en el ámbito del derecho matrimonial. Igualmente, hasta mediados del siglo IV a.C. no se produce el acceso de los plebeyos a las magistraturas, Senado y colegios sacerdotales.

En el Principado, las personas de la clase social elevada, potentiores, son favorecidas en la aplicación del Derecho penal, en relación con el trato dispensado a las personas de extracción modesta.

En el marco de la condición social cabe, asimismo, encuadrar las limitaciones que sufren los libertos, tanto en la esfera del derecho público como privado, si bien es a causa de la relación de patronato que se establece con su antiguo dueño, de donde se derivan mayores restricciones a su capacidad, en parte compensadas por los beneficios que se les atribuyen.

La condición política de senador o magistrado, en Roma o en provincias, implicaba al propio tiempo privilegios y limitaciones. En relación con las limitaciones derivadas de la condición profesional, cabe hacer referencia a los militares, los clérigos, y a los miembros de las corporaciones profesionales afectadas por la prestación de un servicio público, profesionales todos ellos a los que se reconocía, en compensación, el disfrute de determinadas prerrogativas y beneficios. La última causa que afecta a la capacidad jurídica sería la situación de libertad formal.

Las causas limitadoras o modificativas de la capacidad de obrar, no suponen una limitación de los derechos de la persona en el marco 
de su capacidad jurídica, pero si en el ejercicio de las actuaciones que toda persona, por el hecho de serlo, puede realizar en el ámbito de su autonomía. Como primera causa limitativa, señala el A. la edad. La plena capacidad volitiva e intelectual viene determinada por la $\mathrm{pu}$ bertas, 12 ó 14 años, trae consigo la mayoría de edad y, en consecuencia, la desaparición de la tutela de los menores, tutela minorum, la plena capacidad de obrar, si la persona es sui iuris, y la total responsabilidad de las actuaciones realizadas en el marco del Derecho civil y penal: capacidad negocial, procesal y responsabilidad delictual. En esta sede trata el A. los distintos tipos de tutela, testamentaria, legítima y dativa, los poderes del tutor, la necesaria autorización judicial para determinados actos del tutor, como procedimiento de jurisdicción voluntaria, las excusas, fianza, inventario, responsabilidad del tutor, etc.

Respecto de las causas que motivaron el establecimiento de la curatela de los menores, cura minorum, considera el A. que entre estas se encontraría el retraimiento en la realización de transacciones económicas con los menores, con la consecuente restricción del ámbito de su autonomía personal, a la vista de las facilidades que la Lex Laetoria o Plaetoria de circunscriptione adolescentium, del 191 a.C., les atribuyó para cuestionar ante los tribunales la validez de los negocios formalizados. En relación con el beneficio de edad, venia aetatis, a partir de Constantino, siglo IV d.C., se introduce la posibilidad de que los varones mayores de 20 años y las mujeres mayores de 18, que acrediten buenas costumbres, honorabilidad y aptitud para administrar su patrimonio, puedan solicitar un anticipo de mayoría de edad y, por ende, la exención de la curatela. La venia aetatis suponía la plena capacidad de obrar -salvo las actuaciones consistentes en enajenar o donar inmuebles y, con Justiniano, constituir hipotecas, que requiere la autorización del curador-.

Como segunda causa limitativa aparece la enfermedad mental. La enajenación incapacita, de modo absoluto, a la persona que la padece, en el ámbito civil y en el de la responsabilidad penal. Si bien la enajenación sobrevenida, ni disuelve el matrimonio, ni anula el testamento ya otorgado. En la época postclásica se estableció, con carácter general, la regla de la capacidad de obrar de las personas con enfermedad mental, durante sus periodos de lucidez.

En tercer lugar se menciona la prodigalidad. El prodigo es aquella persona que dilapida sus bienes sin medida, poniendo a su familia, y así mismo, en riesgo de subsistencia. A la prohibición de administrar los bienes decretada por el magistrado, se acompaña el nombra- 
miento de un curador, curator, encargado de la gestión y administración de los bienes del incapacitado.

La persona jurídica es analizada a continuación. Afirma el A. la personalidad jurídica del populus romanus, si bien es la soberanía, de la que no se desprende en sus relaciones con los particulares y, su corolario, del no sometimiento, como norma general, al derecho privado, la fundamental diferencia que, en el ámbito patrimonial, le diferencia de las personas físicas. Respecto al fiscus, su régimen jurídico oscila entre el derecho público y el derecho privado, lo que ha llevado a un sector doctrinal a considerarlo un ente jurídico independiente del Estado romano.

Los municipios, colonias, ciudades y provincias son considerados por el A., más que ninguna otra figura jurídica, como el antecedente histórico, del moderno concepto de persona jurídica: a) poseen capacidad de obrar en el marco del derecho patrimonial; b) en el ámbito de las relaciones patrimoniales se rigen, según los casos, por el derecho privado o por el derecho público; c) actúan por medio de sus representantes y d) se rigen por una normativa específica, lex municipalis o lex coloniae, conforme a la que se configura su estatuto jurídico y político.

Sin embargo, no parece que pueda predicarse la personificación jurídica de las asociaciones republicanas, en el ámbito de su autonomía patrimonial, salvo quizás en el caso de las sociedades de publicanos. A lo largo de toda la época clásica se produce un fortalecimiento de su capacidad, que acaba desembocando en una equiparación con la personalidad jurídica de las ciudades. Como requisitos para la constitución de las asociaciones: a) un mínimo de tres personas, b) fin lícito y común a todos los miembros, c) dotación de su lex collegii.

Si poseen personalidad jurídica las fundaciones, esto es, aquél patrimonio o conjunto de bienes destinado, por una persona física o jurídica, al cumplimiento de una finalidad social y duradera. En los primeros siglos, la realidad fundacional se materializó por la vía de los negocios de liberalidad; más tarde con el reconocimiento de las causas pías, piae causae.

Respecto de la herencia yacente, hereditas iacens, se reconoce una cierta personalidad jurídica, en la medida en que puede sufrir aumentos y disminuciones, en atención a los derechos y obligaciones que le sean imputables, durante el tiempo comprendido entre el fallecimiento del causante y la aceptación del heredero. 
El contrapunto a la libertad de la persona era la esclavitud, como institución del ius gentium, común a todos los pueblos. Respecto del fundamento ético y filosófico de la esclavitud, afirma el A. que los grandes pensadores y hombres justos de la civilización clásica, como Sócrates, Platón, Aristóteles, Jenofonte o Séneca, no han sido capaces de cuestionar y sí de justificar una institución a nuestros ojos tan aberrante e indigna como la esclavitud, lacra injustificable en el panorama luminoso de la antigüedad y que concepciones en tantos aspectos liberadoras del ser humano como el cristianismo y el estoicismo, no hayan procedido a su supresión, no obstante el inicio de su progresiva puesta en tela de juicio y limitación (si bien hay que esperar a los albores del siglo XX para contemplar su extinción definitiva), la manifiesta consideración para estos pensamientos filosóficos de los esclavos como seres humanos, y las disposiciones adoptadas por los emperadores cristianos y estoicos favorecedoras de la clemencia y de la libertad, o asimismo que los autores citados, no hayan realizado una valoración positiva, del trabajo físico o material de la persona, que nosotros consideramos un hecho social básico y dignificador de la condición personal, nos debe hacer reflexionar sobre la mutabilidad de la idea de lo justo y sobre la consideración del derecho como un punto de vista -contingente, limitado, perfectible y criticable- sobre la justicia. Es por ello por lo que cabría subrayar que la historia de la humanidad se nos presenta, también en este punto, como un proceso continuado y gradual, con sus hitos, altibajos y retrocesos, en el logro de mayores cotas de libertad y de justicia.

Respecto a la consideración de Roma como sociedad esclavista, entendiendo por tal aquella basada en la producción de los esclavos, en la explotación económica de su trabajo como servil y en la lucha de clases, considera el A. que ello viene matizado por la historia de la experiencia jurídica romana y por la consideración de la esclavitud como instituto del ius gentium.

En cuanto a la posición jurídica del servus, en el ámbito familiar se encuentra sometido a la potestas del paterfamilias. En las relaciones patrimoniales, los servi no podían tener nada propio. En el viejo ius civile, los sometidos a potestad, libres o esclavos, podían mejorar pero no empeorar la posición del pater. Esta situación injusta fue modificada por el pretor mediante las actiones adiecticiae qualitatis. En el ámbito religioso, se establece el carácter vinculante del votum; se considera locus religiosus su sepulcro y se autoriza su pertenencia a asociaciones funerarias. En el campo procesal, se permite reclamar ante el magistrado el reconocimiento de su libertad. En el campo negocial destaca la capacidad reconocida a los esclavos públicos, que 
actúan como representantes de la administración en la conclusión de determinados actos jurídicos y como actores en procesos que afectan a los intereses generales. En la esfera penal es responsable de los delitos públicos que comete. En el campo de los delitos privados, responsable es el dominus, salvo que opte por la noxae deditio. En la esfera del derecho de sucesiones puede ser instituido heredero siempre que al propio tiempo se le conceda la libertad.

Trata a continuación el A. las causas de esclavitud, señalando: a) la cautividad en guerra, como la primera y más relevante; b) el nacimiento; c) la deserción; d) la exclusión del censo; d) la condena por insolvencia hasta la lex Poetilia Papiria del 326 a.C.; e) por hurto manifiesto; f) por injurias a un embajador extranjero; g) el ciudadano partícipe en una venta de sí mismo como esclavo, con objeto de participar en el precio; h) según el Senadoconsulto Claudiano del 52 d.C., el ciudadano que mantiene relaciones sexuales con esclavas ajenas, después de la advertencia del dueño de éstas; i) los condenados a pena capital, trabajos forzados o a la lucha de gladiadores; j) violación de los deberes del patronato.

Seguido analiza los distintos modos de extinción de la situación de esclavitud, es decir, aquellos actos de iniciativa privada del dominus, mediante los cuales éste concede la libertad al servus: manumisiones solemnes, manumisiones no solemnes y por disposición legal. Los libertos tenían notables limitaciones a su capacidad de obrar tanto en el marco del derecho público como, aunque en menor grado, en el campo del derecho privado.

Comparte el A. la razones políticas expuestas por Gaudemet que motivaron la publicación de las leyes Fufia Caninia del 2 a.C., Aelia Sentia del 4 d.C. y Iunia Norbana del 19 d.C., la necesidad de evitar, o frenar al menos, el acceso a la ciudadanía de extranjeros culturalmente muy diferentes de los romanos, a fin de evitar que ello supusiese un trastorno relevante en el equilibrio político romano.

Centra el A. su atención en el status civitatis. Para el Ordenamiento Jurídico de Roma, en materia de nacionalidad, el hombre libre, o bien era ciudadano romano, civis, o bien era un no ciudadano, peregrinus, o bien bárbaros, barbari, o enemigos, hostes. Una posición intermedia ocupaban los latinos.

$\mathrm{Al}$ ciudadano romano, civis romanus, como miembro de pleno derecho de la civitas romana, se le reconocen todos los derechos en el ámbito político y privado, conforme a lo establecido, en el antiguo ius quiritium y, en el posterior, ius civile. La ciudadanía se adquiere: a) 
por nacimiento; b) por ley; c) por concesión discrecional de la autoridad política; d) por manumisión. La ciudadanía se perdía: por pérdida de la libertad, por fijación de residencia en el territorio de un país extranjero, por renuncia y como pena prevista en un proceso criminal.

Los peregrinos eran personas libres que, no obstante, tener fijada su residencia en el territorio romano, no ostentaban la ciudadanía romana. Se les reconoció el ius commercii, la testamentifactio activa, el ius connubii y el ius actionis.

Una posición intermedia, era la ocupada por los latinos. Los latinii veteres estaban equiparados a los ciudadanos romanos, salvo en el desempeño de cargos públicos. Posición semejante a éstos era la que ostentaban los miembros de las colonias fundadas por Roma.

Muy oportuna resulta la exposición del negocio jurídico, pues aunque no fuera formulado ni por los juristas clásicos ni por los justinianeos sino por la moderna ciencia jurídica, a partir de la doctrina pandectística alemana del siglo XIX, tal construcción se asienta en las soluciones concretas dadas por los juristas romanos en tema de contratos y de testamentos y resulta indudable su actualidad en la civilística.

Se hace eco del primitivo formalismo de la actividad negocial, influido por la intervención en el mismo del Colegio Pontifical. Dicho formalismo, esencial para la producción de efectos jurídicos, relegaba a la auténtica voluntad de los intervinientes en la relación negocial. Sin embargo, la voluntad negocial se impondrá por distintas razones: a) necesidades del tráfico comercial; b) por la jurisdicción de los pretores; c) aparición de criterios específicos de interpretación como favor testamenti, favor dotis, favor libertatis o favor debitoris; d) las relaciones comerciales entre Roma y otras comunidades; e) la bona fides.

El concepto de negocio jurídico, elaborado por la pandectística, engloba el hecho natural, el hecho jurídico, el acto jurídico y la relación jurídica. Analiza el A. las clases de negocios jurídicos y los elementos esenciales del negocio jurídico.

Estudia los elementos accidentales del negocio jurídico: condición, término y modo, poniendo de relieve, una vez más, cómo algunas de las disposiciones contenidas en los numerosos textos romanos se recogen en el CC. El análisis de la materia relativa a la invalidez del negocio jurídico: convalidación y conversión, presenta una especial dificultad debido a: a) la distinta eficacia reconocida a determinados 
negocios por el derecho civil y el derecho pretorio; b) la ausencia de una terminología unitaria para referirse a la invalidez y; c) las distintas soluciones que se dan en cada etapa histórica.

La Unidad didáctica 5 (págs. 153-192) titulada Acciones y procedimiento, se inicia con las características generales del sistema de los juicios privados y de la cognitio extraordinaria. Acertado nos parece la contraposición jurisdicción contenciosa-jurisdicción voluntaria, de la que el A. es un reputado especialista, así como el tratamiento del arbitraje. Aborda los conceptos procesales de actio, iurisdictio y iudicatio, destaca la característica del Derecho Romano como un Derecho de acciones, pues era necesario que existiera una acción para poder pedir la protección de los derechos. De modo que gráficamente se puede decir que la acción es antes que el derecho subjetivo. Define la acción como un medio jurídico-procesal a favor del demandante a través del que puede pedir protección a los órganos jurisdiccionales establecidos al efecto. Analiza los tres tipos de procedimientos que se sucedieron históricamente en Roma -acciones de la ley, formulario y cognitio extraordinaria- de los que derivan los principios procesales modernos como principios de audiencia, inquisitivo, de contradicción, la carga de la prueba corresponde al que afirma no al que niega, etc.

La Unidad didáctica 6 (págs. 193-250) titulada Derecho de cosas, se abre con un interesante estudio sobre el concepto de cosa y su acotamiento en el orden jurídico, concluyendo que resulta problemático porque las exigencias sociales de cada época histórica influyen y condicionan el mundo del derecho, transformado sus instituciones. También nos parecen muy sugestivas las páginas que el A. dedica a la clasificación de las cosas, en las que no escatima esfuerzos para presentarnos su criterio personal sobre problemas concretos y controversias deducidas a la luz de los numerosos textos citados y escogidos.

Muy acertado nos parece, en términos pedagógicos, la exposición de la posesión previa a la de la propiedad. Ésta aparece ante las demás personas como un reflejo de la propiedad o de otro derecho real, que le faculta para ejercer la disponibilidad que comporta su tenencia, con abstracción de que, en la realidad, le corresponda o no la titularidad del derecho que aparenta. Respecto de la discutida naturaleza jurídica, el A. acoge la posición de Savigny frente a la de Ihering, de acuerdo con las fuentes romanas que consideran la posesión como un hecho, añadiendo a los argumentos de Volterra, que la posesión no se hereda por los herederos voluntarios, que no se subrogan 
en la posición de poseedor que sobre los objetos hereditarios tuviese su causante, por lo que deben volver a iniciar de nuevo la posesión de cada uno de los objetos hereditarios.

La adquisición de la posesión se efectúa con la concurrencia simultánea del corpus y el animus. Observa el A. que Paulo, Gayo y Juliano, estudian la posesión en relación con la usucapio. Ulpiano lo hace en relación con los interdictos y, con carácter general, los juristas tienden a detenerse más en la vertiente procesal del hecho posesorio, en el marco de los comentarios al Edicto, que en el análisis sustantivo de la institución. Subraya la evolución materialista hacia una concepción espiritualista tanto del corpus como del animus en la adquisición y en la retención de la posesión. Continúa con el apartado dedicado a la protección de la posesión, cuyo origen puede estar bien en la tutela interdictal dispensada a los poseedores del ager publicus, o bien en la protección provisional de la posesión de la cosa objeto de litigio, res litigiosa, mientras no se dictaba la sentencia definitiva.

Muy interesantes nos parecen las consideraciones que hace el A. sobre la distinción entre derechos reales y personales. Desde una topología de los conceptos jurídicos, señala que dicha distinción la contemplaron los juristas romanos desde un punto de vista del proceso, trasladándola al campo de las acciones: la actio in rem como tutela de los derechos reales; la actio in personam para proteger los derechos subjetivos de obligación. La nítida distinción clásica entre ambas categorías, fue objeto de atenuación en el derecho justinianeo, aunque se mantiene, no exenta de polémica doctrinal, en el derecho actual. Por otra parte, frente al actual sistema de libertad de constitución de los derechos reales, cuestionado por un sector de la doctrina, en Derecho Romano, rige el sistema del numerus clausus, conforme al cual los posibles derechos sobre las cosas vienen determinados por la ley.

Respecto al concepto de propiedad, considera el A. que es un concepto dinámico y no estático. La génesis de la propiedad se identifica con las profundas transformaciones sociales y económicas que en su dilatada existencia sufre el Derecho Romano. La historia de la propiedad, desde la originaria propiedad romana hasta nuestros días, se podría describir, de forma sintética, como una continuada atenuación de su carácter individualista en correspondencia con la progresiva profundización en el contenido social, lo que ha supuesto una nueva configuración de la institución. Diáfana es la exposición que el A. dedica a las limitaciones de la propiedad. La acción reivin- 
dicatoria es la acción civil concedida al propietario no poseedor de la cosa contra el poseedor no propietario. Subraya la diferente condición del demandado en la acción reivindicatoria, en las distintas etapas históricas y procedimientos: presunto propietario, en el procedimiento de las acciones de la ley, poseedor en el procedimiento formulario, poseedor o tenedor, en el procedimiento cognitorio o extraordinario. Sigue el análisis de la acción negatoria; la acción de contención de las aguas pluviales; la denuncia de obra nueva; la caución por el daño temido.

A propósito de los modos originarios de adquisición de la propiedad, observa el A. que la moderna distinción entre modos originarios y modos derivativos de adquirir la propiedad, es ajena a los primeros tiempos del Derecho romano, donde se operaba con la idea elemental de que se transmitía la cosa misma, y no un derecho de propiedad sobre la cosa. Habría que esperar al surgimiento de la compraventa consensual para que se opere ya con la idea de la transmisión del derecho.

En materia de ocupación, cabe destacar, a mi juicio, la precisión con la que el A. analiza tanto el concepto como los diferentes supuestos de cosas susceptibles de ocupación. Fruto de profundas reflexiones son las páginas que el A. dedica a la accesión, donde destaca que no existe en Derecho Romano una teoría general, ni un concepto unitario de accesión, sino una variada casuística en la materia, que se incardina en el marco de los modos naturales de adquirir la propiedad. Tampoco hay una regla invariable para determinar qué es lo principal y qué lo accesorio. En unas ocasiones se considera principal lo que existía con anterioridad. En otros supuestos se entiende que es cosa principal la de mayor valor económico, existiendo asimismo supuestos en los que, a juicio de la doctrina, el criterio legal romano resulta discutible. Se ha afirmado que, con carácter general, se considera cosa principal aquella que determina la función económico-social del todo. Los distintos tipos de accesión en el Derecho Romano se incardinan en: a) accesión de una cosa mueble a otra cosa mueble; b) accesión de una cosa mueble a una cosa inmueble; y c) accesión de una cosa inmueble a otra cosa inmueble. Otros modos originarios son la especificación y la confusión y commixtion; por último, trata el A. la adquisición originaria de frutos.

Analiza el A. los modos derivativos de adquirir la propiedad. La mancipatio, negocio arcaico, formal y abstracto de transmitir la propiedad, es considerado por el A. anterior a las XII Tablas. A partir de las XII Tablas el pronunciamiento de palabras determinadas, nun- 
cupata pecunia, cumple una función traslativa de propiedad, y se configura como un negocio lleno de posibilidades, en atención a su carácter abstracto en el marco del derecho patrimonial, familiar o hereditario.

Respecto de la naturaleza jurídica de la in iure cesio, considera el A. que durante los primeros siglos, los comparecientes, puestos previamente de acuerdo, entablarían un proceso formalmente ficticio, pero sustancialmente del todo regular, ante el magistrado que presidía la litis, que concluiría mediante una resolución, addictio, en el marco de una estructura procesal.

Al tratar de la traditio, después de analizar el concepto y los requisitos, concretamente en la época postclásica, observa el A. que se cuestiona la concepción causal de la traditio, considerándose que basta la concorde voluntad de transmitir y adquirir la propiedad, sin necesidad de explicitar la causa del acuerdo entre las partes. Esta concepción abstracta de la traditio encuentra su reflejo en las fuentes justinianeas. Observar que este será el sistema seguido por el Código civil de Napoleón. Nuestro Código civil, por el contrario, sigue la formulación clásica de la teoría causal, bajo la denominación de teoría del título y del modo. Por último, trata el A. la usucapión y la prescripción. La adquisición de la propiedad por usucapión supone una clara manifestación de la fuerza sancionadora que se reconoce, por el ordenamiento jurídico, al trascurso del tiempo de posesión de una cosa. Se trata con ello de remediar la posición en la que se encuentra el adquirente de una cosa que, o bien la ha adquirido de buena fe de un no propietario; o bien la ha adquirido sin la preceptiva mancipatio o in iure cessio. Paulatinamente la jurisprudencia establecerá los requisitos de la usucapión: res habilis, bona fides, tempus, possessio y iusta causa o titulus. Como medio procesal para defender la posesión de los fundos provinciales, la jurisprudencia creó a imagen de la usucapio, la praescriptio longi temporis. Justiniano, en el año 528, funde las dos instituciones, creando además la praescriptio longissimi temporis.

Seguido analiza el derecho real de servidumbre. Derivado del derecho de propiedad, la jurisprudencia romana ha ido configurando un conjunto o elenco de derechos reales, cuyo principal rasgo diferenciador respecto de aquella consiste en que recaen sobre una cosa cuya propiedad pertenece a otra persona. Los iura in re aliena, en su condición de derechos reales, presentan las dos principales características de éstos: reipersecutoriedad y ergaomnicidad. Las servidumbres prediales constituyen el ius in re aliena más antiguo del 
Derecho Romano. El contenido de la servidumbre ha de tener por objeto la utilidad o servicio, o tolerar o no hacer algo.

Como es sabido, en el Derecho Romano no se formula primero el principio o la regla y después se aplica a los casos, sino que el procedimiento, en vez de ser deductivo, es inductivo, en atención a que parte de las soluciones que se dan a los casos que se plantean como problemáticos y sólo una vez que haya producido una reiteración de soluciones análogas a casos semejantes, se van formulando reglas o principios, que constituyen el resultado de la cristalización de las respuestas concretas, cuando éstas son reiteradas en la resolución de casos parecidos.

Pues bien, los más importantes principios y reglas de aplicación al conjunto de las servidumbres son: 1) Nadie puede constituir una servidumbre sobre un fundo propio a favor de otro fundo propio, nemini res sua servit; 2) La servidumbre consiste en tolerar o en no hacer algo, servitus in faciendo consistere nequit. Dicha regla tiene una excepción, la servitus oneris ferendi, donde el titular del fundo sirviente viene obligado a un hacer; 3 ) Una servidumbre no puede constituirse sobre otra servidumbre, servitus servitutis esse non potest; 4) Vecindad entre ambos fundos, vicinitas; 5) La servidumbre debe proporcionar siempre una utilidad al fundo dominante, utilitas; 6) Las servidumbres son indivisibles; 7) El ejercicio de la servidumbre debe efectuarse de tal manera que cause el menor trastorno o perjuicio al titular del fundo sirviente; 8) La servidumbre es un derecho inherente al fundo, no puede ser objeto de negocios jurídicos, con independencia del fundo.

Sigue el estudio de las clases de servidumbres: rústicas y urbanas. Las rústicas son las primitivas, ya que surgen en la Roma más antigua, en la que la sociedad respondía a un modelo de fines fundamentalmente agrarios. Las urbanas se establecían sobre fundos, llamados solares, con la finalidad de favorecer, con carácter general, las necesidades derivadas de la edificabilidad y urbanización en las urbes, si bien la servidumbre urbana, strictu sensu, lo fue siempre en consideración al edificio favorecido o gravado por la servidumbre, y no a la ubicación del terreno, en zona rústica o urbana, en el que se asiente la construcción o edificio objeto de la misma. Por último, analiza el A. la constitución, defensa y extinción de las servidumbres.

A continuación analiza las servidumbres personales: usufructo, uso, habitación y trabajo de los esclavos. Respecto del polémico alcance del «salva rerum substantia», considera el A. que si bien en un primer momento, la obligación de respetar la sustancia de la cosa en- 
tregada en usufructo era interpretada de forma muy estricta por los juristas, de forma progresiva se produce un lento abandono de la concepción primitiva que se materializa en una atenuación del originario rigorismo jurisprudencial, en aras de una mayor flexibilidad en el curso de la época clásica.

El propietario, nudus propietarius, conserva las facultades inherentes a su derecho de propiedad, siempre que no perjudique los derechos del usufructuario. Por su parte, el usufructuario, tiene las facultades de usar y disfrutar una cosa ajena, utendi et fruendi. El usufructuario no puede transmitir ni inter vivos ni mortis causa su derecho, simplemente se le permite ceder inter vivos, de forma gratuita o remunerada, el ejercicio de su derecho.

El usus, es aquel derecho real en cosa ajena que faculta a su titular, denominado usuario, a usar, es decir, utilizar una cosa de otro sin derecho a los frutos que produzca. La jurisprudencia permitiría el consumo propio o familiar, sin que pudiesen por ello ser objeto de enajenación o comercialización.

El derecho real de habitación, considera el A. que surge para dar solución a los casos en los que la casa paterna se adjudicaba en propiedad a uno de los hijos, al propio tiempo que se establecía en el testamento, por el otorgante, que sus otros hijos pudiesen tener el derecho de utilizar una habitación de la casa. Su titular puede ceder su ejercicio a título oneroso, pero no gratuitamente.

Por último se aborda el estudio de los derechos reales de garantía. En primer lugar se analiza la fiducia que es la forma más antigua de garantizar, de forma real, el cumplimiento de una obligación con el acreedor por parte del deudor. Esta es la denominada fiducia cum creditore, distinta es la fiducia cum amico contracta, en tiempos de turbulencia política, a fin de evitar la confiscación del patrimonio, eran frecuentes las transmisiones de la propiedad de las cosas a amigos y a personas de confianza, con ruego de su custodia, y posterior devolución, en un momento político más favorable para el transmitente.

En el pignus datum, el deudor, o un tercero en consideración a él, entregaba una cosa al acreedor, datio pignoris, transfiriéndole sobre la misma la posesión, en garantía del cumplimiento de una obligación. $\mathrm{El}$ acreedor pignoraticio defiende su posesión con la tutela interdictal. En el supuesto de incumplimiento de la obligación garantizada, el acreedor podrá convertirse en propietario de la cosa pignorada, en virtud del pactum de lex commissoria, prohibido por Constantino, o 
bien, enajenar la prenda, ius distrahendi o ius vendendi, y detraer del precio recibido la cantidad que el deudor pignorante le adeudaba.

La hipoteca o pignus conventum es un acuerdo o convenio entre las partes de una relación obligatoria, conforme al cual, el deudor hipotecante garantiza el cumplimiento de su obligación con una cosa propia o de un tercero, con su consentimiento, sin que se produzca traspaso de la posesión y con el compromiso de entregarla al acreedor en el supuesto de que no se cumpla la obligación garantizada.

El origen de la hipoteca se encuentra en los arrendamientos rústicos. Dado que la entrega en posesión de los objetos utilizados para la labranza impediría su utilización por el arrendatario, se acordaba que, en estos casos, no se producía la entrega de tales cosas en garantía. El arrendador quedaba protegido por el interdicto Salviano, más tarde con la actio serviana y, por último, con la actio hypothecaria.

La hipoteca se generalizó en época clásica, y en derecho justinianeo la hipoteca tácita constituye una práctica habitual. Junto a éstas, las hipotecas legales se clasifican en generales y especiales. Las primeras afectan al patrimonio en su conjunto, en época clásica, la que garantiza los créditos del fisco y la del acreedor refaccionario; en época postclásica y justinianea, a favor del menor o del pródigo sobre los bienes del tutor o curador; a favor del legatario o fideicomisario sobre la herencia; a favor de los hijos del primer matrimonio sobre los bienes del padre o madre casados en segundas nupcias, en garantía de los derechos hereditarios; a favor de la mujer sobre el patrimonio del marido, en garantía de devolución de la dote; a favor de la Iglesia sobre el patrimonio de los enfiteutas, por posibles daños o deterioros en los fundos cedidos; las especiales gravan bienes determinados.

La constitución de dos o más hipotecas sobre la misma cosa, viene regulado por el principio prior in tempore potior in iure. El orden de antigüedad de las hipotecas puede verse afectado por diversas circunstancias: por el ius offerendi; por la existencia de hipotecas privilegiadas, como a favor del fisco, a favor del acreedor refaccionario, la constituida en documento público, instrumenta publice confecta, o en documento privado suscrito por tres testigos, instrumenta quasi publice confecta, a favor de la mujer sobre el patrimonio de su marido, para garantizar la restitución de la dote.

La libertad de forma en la constitución de la hipoteca, con la consiguiente inexistencia de un sistema de inscripción y publicidad for- 
mal del crédito constituido, unido al hecho del número creciente de hipotecas legales y privilegiadas, supusieron un lastre en el desarrollo del crédito hipotecario, y en el eficaz aseguramiento de los créditos por medio de esta forma de garantía real. Se adoptaron distintas medidas tendentes a disminuir la inseguridad del crédito hipotecario como la preferencia de las hipotecas formalizadas en documento público o quasi público; y la tipificación del crimen stellionatus, mediante el cual se persiguen, entre otros supuestos, las actuaciones dolosas y fraudulentas en el marco del crédito hipotecario.

La Unidad didáctica 7 (págs. 251-298) titulada Derecho de obligaciones, se inicia con el acertado análisis introductorio que hace el A. y que completado con lo expuesto a propósito de la distinción entre derechos reales y personales, resulta esclarecedor desde un punto de vista pedagógico. Sigue la clarificación del concepto de obligación, donde observa que el significado y el propio contenido del concepto de obligación están hoy tan enraizados en la conciencia social, que no es preciso poseer conocimientos jurídicos para tener una noción aproximada de lo que con este término quiere expresarse. La idea de obligación está vinculada al comportamiento humano, asumiendo el Derecho la regulación de una parcela o manifestación concreta de esa conducta. Por ello, junto con obligaciones jurídicas, reconocidas por el Derecho y provistas de trascendencia jurídica, existen otras que sólo presentan una significación social o moral. Son las llamadas obligaciones sociales y obligaciones morales.

En sede de fuentes de las obligaciones, observa el A. que la no inclusión de la ley como fuente formal de obligaciones obedece a la singular consideración otorgada a la voluntad como fuente generadora de obligaciones, y a que, en definitiva, es siempre la ley la que sanciona el nacimiento de la obligación, cualquiera que sea la causa de la que ésta derive, dado que la obligación existe sólo en la medida en que el Ordenamiento Jurídico dispone que puede exigirse ante un juez o tribunal.

En Derecho Romano, el daño causado contra derecho, damnum iniuria datum, era un delito privado, de ahí que quedase incurso en el ámbito de las obligaciones derivadas de delito en la cuatripartición gayana. La posterior despenalización, con excepciones, de este tipo de ilícito, supuso, en consecuencia, su configuración, con carácter general, como una fuente específica de obligaciones civiles en el Código civil. Por otra parte, determinados supuestos considerados como cuasidelitos en las fuentes romanas, como podían ser los daños pro- 
ducidos por negligencia en casos concretos, han pasado a engrosar o bien la categoría de ilícitos penales, al ser tipificados en el Código penal, o bien la categoría de ilícitos civiles no penados por ley, englobados en la esfera de la responsabilidad extracontractual.

Claro, completo y muy pedagógico resulta el tratamiento que el A. otorga a las clases de obligaciones. En sede de obligaciones naturales, considera el A. que aunque el Código civil no hace referencia a ellas, podrían encuadrarse en esta categoría las deudas nacidas de juegos de suerte, envite o azar; los intereses no pactados de forma expresa en los préstamos y la deuda prescrita, dado que si bien la prescripción extingue la acción y el derecho a reclamar el crédito, cabe considerar que subsiste la obligación del deudor entendida como obligación natural.

En materia de transmisión de obligaciones, destaca el A. que el carácter restrictivo de la regulación de cesión de créditos y deudas, propio de los primeros siglos, produjo una ralentización en el tráfico económico, que se procuro obviar mediante el recurso a fórmulas indirectas con las que se pretendió la obtención, en la práctica, de la finalidad perseguida de transmisión de las obligaciones.

Muy clara y precisa es la exposición que hace el A. sobre la garantía de las obligaciones, distinguiendo entre aquéllas personales provenientes del propio deudor -pacto de constituto, arras, cláusula penal y juramento-, de aquéllas provenientes de un tercero-fianza (sponsio, fideipromissio y fideiussio), mandato de crédito-, finaliza con el patrimonio del deudor como garantía. Sigue la extinción de las obligaciones, donde el A. distingue entre modos ipso iure que extinguen la obligación de forma automática a partir del momento de su producción, con la consiguiente desaparición del crédito del sujeto activo y de la responsabilidad del sujeto pasivo -solutio-, y modos ope exceptionis en los que, en rigor, no cabe afirmar que se produzca una extinción propiamente dicha del derecho de crédito del sujeto activo, sino que la realización de un determinado acto jurídico faculta al deudor para alegarlo como excepción que paraliza o enerva la acción del demandante acreedor, al que se impide exigir judicialmente al deudor el cumplimiento de la prestación -compensación, pacto de no pedir-.

Clarificador resultan las observaciones preliminares dedicadas a la responsabilidad contractual y extracontractual o aquiliana donde destaca el A. que la construcción doctrinal y regulación legislativa de la responsabilidad contractual, que es aquella que tiene lugar en el marco de las relaciones entre acreedores y deudores, constituye, en 
sus líneas esenciales, el resultado de la labor realizada por la pandectística alemana y, con posterioridad, por la moderna civilística, sobre los casos y soluciones contenidos en las fuentes romanas. Por otra parte, observa que hay otras fuentes de las obligaciones, como los cuasicontratos o la ley, diferentes del contrato, a las que cabe asimismo aplicar la teoría y la normativa propia de la denominada responsabilidad contractual. Además, cabe observar que las normas sobre responsabilidad por incumplimiento contractual son en la actualidad, como así sucedía también en Derecho Romano, de carácter dispositivo, salvo la no exigibilidad de responsabilidad por dolo, pactum de dolo non praestando, al considerarse contrario a las buenas costumbres.

En sede de criterios de responsabilidad: dolo, culpa, fuerza mayor, caso fortuito, mora, considera el A. a propósito de la custodia, que es probable que la asunción de la responsabilidad agravada en los supuestos de custodia hubiera sido, en los primeros tiempos, el resultado de un pacto inter partes, para acabar siendo considerada una responsabilidad inherente a determinados tipos de relaciones contractuales, en los que el obligado respondería de los riesgos de robo y daños causados por terceros, al margen de que haya actuado o no de forma culposa, es decir, con independencia de su diligencia, diligentiam praestare. La discutida responsabilidad por custodia, supondría por ello la asunción de un riesgo con independencia de la noción de imputabilidad.

La Unidad didáctica 8 (págs. 299-340) titulada Derecho de los contratos, a propósito de contratos y pactos, observa el A. que mientras en Derecho actual se formula una noción abstracta de contrato y los términos convenio, pacto, consentimiento o contrato son términos equivalentes, el Derecho Romano clásico nos ofrece una lista de contratos, pues sólo son considerados como tales aquellos convenios a los que el ordenamiento atribuye el efecto de crear obligaciones.

La configuración y definición de la categoría de contrato es, por otra parte, fruto de un proceso lento y progresivo de la ciencia jurídica que, con apoyo en las fuentes romanas, se ha ido entretejiendo en distintas épocas y por diversas escuelas. De este modo, el principio según el cual de cualquier forma en que el hombre quiera obligarse quede obligado, abandona definitivamente la exigencia de cualquier otro requisito, formal o material, y se erige en causa suficiente para contraer una obligación. Este principio de libertad formal, junto con el principio de libertad contractual, se constituyen como los dos pilares sobre los que se asienta todo el edificio del sistema contractual 
moderno, recogido con escasas diferencias por todas las codificaciones civiles europeas.

Analiza el A. la clasificación de los contratos, deteniéndose en cada una de las figuras que los integran. A propósito del mutuo, señala el A. que en Derecho Romano, el carácter unilateral del mutuo tiene carácter absoluto, en el sentido de que no cabe hablar de obligaciones ni de responsabilidad del mutuario. En el préstamo actual no surgen, en vía principal, obligaciones para el prestamista y sólo en vía accesoria cabría exigírsele responsabilidad si las cosas dadas en mutuo adoleciesen de vicios o defectos que produjesen daños al prestatario. Amplio tratamiento dedica el A. a los contratos consensuales, en especial, a la compraventa, consecuencia de su importancia social y económica. En conexión histórica con la compraventa se encuentra la permuta, ampliamente analizada también por el A., destaca que en el momento actual, se asiste a una revalorización de la figura en el marco del urbanismo y de la legislación agraria, ligada a factores como la inestabilidad económica, la inflación, el auge urbanístico o el elevado precio de los terrenos edificables. Instituciones como la concentración parcelaria, o la permuta forzosa de fincas rústicas, en el ámbito del Derecho agrario, o la reparcelación y, de modo especial, la permuta de cosas futuras, consistente en el contrato de intercambio de solar edificable por piso o local de negocio a construir sobre terreno permutado, en la órbita del derecho urbanístico, han supuesto una especial revitalización de esta figura jurídica.

La Unidad didáctica 9 (págs. 341-374) titulada Derecho de familia, analiza la evolución de la familia romana. De la familia agnaticia, o personas que integran la familia sometidas a la autoridad del paterfamilias, se pasa a la familia cognaticia, o personas unidas por vínculos naturales o de sangre, por efecto de la procreación o por tener un tronco común. La relación que une a un cónyuge y los parientes consanguíneos del otro cónyuge se denomina afinidad.

Destaca el A. la singularidad de la patria potestad como institución propia de los ciudadanos romanos, no parangonable a la de ningún otro pueblo. Se muestra partidario de la communis opinio en cuanto a la configuración de la familia romana en época arcaica. El carácter absoluto de la potestad paterna se vería limitado por las mores maiorum, el iudicium domesticum, la nota censoria, el progresivo reforzamiento de la posición de los hijos sometidos a patria potestad y el cristianismo.

La presunción de paternidad prevista en las fuentes romanas ha pasado al Código civil. Los hijos extramatrimoniales podían ser legi- 
timados: a) mediante adopción, por el padre natural; b) por subsiguiente matrimonio del padre con la madre natural; c) mediante la donación de un patrimonio suficiente para que el hijo, o el esposo de la hija natural, pudiera asumir el cargo de decurión en los senados municipales.

Se detiene el A. en la figura de la adopción, distinguiendo entre la antigua adrogatio y la posterior adoptio. La primera tiene una estructura y una finalidad eminentemente pública. En época clásica se permitió que pudiesen ser objeto de arrogación, las mujeres y los impúberes; igualmente, se reforzaron, por una constitución de Antonio Pio, las garantías para evitar el fraude y proteger tanto al arrogado como a los herederos del arrogante. La adoptio supone un cambio de potestad familiar en la persona de un alieni iuris a favor del adoptante. En derecho justinianeo, se permite a la mujer adoptar; se exige que el adoptante tenga al menos 18 años más que el adoptado.

Contrapunto de la adopción es la emancipación, consistente en un acto de carácter voluntario del titular de la patria potestad, en virtud del cual renuncia a la potestad de un hijo o hija, confiriéndole la condición de sui iuris. No obstante, el derecho clásico y, en especial, el derecho postclásico, prevé una serie de supuestos de mancipaciones forzosas.

Sigue el estudio de la capacidad patrimonial de los hijos de familia. La única persona que tiene una plena capacidad jurídica y de obrar es el paterfamilias. Sin embargo, constituía una práctica muy antigua la concesión por el paterfamilias de una parte de sus bienes al hijo o hija y al esclavo a título de peculium, lo cual independiza económica y socialmente a quien lo recibe. Examina el A. los distintos tipos de peculio: profecticium, castrense, quasi castrense y adventicium.

Analiza el A. el matrimonio y su régimen patrimonial. Afirma que el matrimonio como toda institución que tiene una tradición de siglos es un producto histórico. Delimita los diversos vocablos utilizados por las fuentes para referirse a la realidad jurídica y social que constituye el matrimonio: matrimonium, nuptiae, consortium, coniunctio, communicatio, societas, pactum, foedus, etc. Igualmente estudia los requisitos e impedimentos para contraer matrimonio. Expone las distintas posiciones doctrinales sobre el debatido tema de la naturaleza jurídica del matrimonio.

Elemento esencial del matrimonio es, al menos en época clásica, el consentimiento. La confarreatio, la coemptio y el usus son formas 
de incorporación de la mujer a la familia del marido. A diferencia de lo que sucede en época arcaica y republicana, a fines de ésta, aumenta el matrimonio libre, con régimen de separación de bienes y no integración de la mujer en la familia del marido. Las diferencias entre matrimonio y concubinato residen, en opinión del A., en la ausencia de affectio maritalis y de dote; destaca la legislación matrimonial de Augusto como la causa de su difusión durante la época imperial, así como el esfuerzo de los emperadores cristianos para facilitar su transición a relaciones matrimoniales. Respecto de los esponsales, en época arcaica se formalizan a través de una sponsio de carácter penal en caso de incumplimiento por parte de la mujer; en época clásica, es un vínculo moral con determinados efectos jurídicos, basta con el mero consentimiento; en época postclásica, por influencia del cristianismo aumentan los efectos jurídicos de los esponsales y se admiten sanciones pecuniarias en caso de incumplimiento.

La unión conyugal genera derechos y obligaciones para los contrayentes, de orden personal y patrimonial: a) la condición de legítimos de los hijos procreados en el matrimonio; b) la consideración de la esposa, en los matrimonios cum manu, a efectos personales y patrimoniales, como una hija de la persona que ostentase la condición de paterfamilias; c) prohibición de donaciones; d) se presume que el incremento patrimonial de la mujer casada, constante matrimonio, procede de su marido; e) el beneficium competentiae; f) prohibición de ejercer acciones penales e infamantes entre cónyuges y g) recíprocos derechos sucesorios, así como derechos a alimentos.

En sede de matrimonio expone la institución de la dote, describe magistralmente su evolución, originariamente constituía una auténtica donación que el marido adquiría definitivamente; en el derecho clásico estos bienes que recibe el marido del padre de la mujer -profecticia-, de la misma mujer o de un tercero-adventicia-son finalistas, ad sustinenda onera matrimonii y, por último, en época justinianea se considera que los bienes dotales pertenecen en propiedad a la mujer. En el ámbito de la restitución dotal, el marido tenía derecho al beneficium competentiae.

Como causas de disolución del matrimonio se mencionan: a) fallecimiento de uno de los cónyuges; b) incapacidad sobrevenida, consistente en la pérdida de la libertad, ciudadanía o adopción del yerno o de la nuera por parte del suegro y c) pérdida de la affectio maritalis.

La voluntad contraria a la continuación de la relación conyugal se denomina repudium, y al efecto derivado del repudium, consistente en 
la cesación del vínculo entre esposos, se denomina divortium. La libertad de divorcio fue casi total hasta comienzos del siglo IV, si bien los divorcios sin causa justificada o el abuso del divorcio fueron objeto de reprobación social ya desde la República. En la época postclásica, la influencia de la filosofía cristiana, supuso una reacción frente a la libertad para disolver el vínculo. Justiniano distingue cuatro figuras de divorcio: a) con justa causa, es decir, el derivado de una actuación culposa de la otra parte; b) sin justa causa, que es objeto de sanciones; c) por mutuo acuerdo, que también es objeto de sanciones; d) fundamentado en causa no imputable a ninguno de los dos cónyuges.

La Unidad didáctica 10 (págs. 375-408) titulada Derecho de sucesiones, se abre con el objeto de la herencia que constituye una unidad por encima del conjunto de elementos que la integran. Distingue la sucesión testamentaria, la intestada y la legítima o forzosa, dentro de ésta la legítima formal y la legítima material. Analiza las etapas históricas de la herencia: a) etapa arcaica, donde expone las tesis de Bonfante, Kaser y Biondi; b) etapa clásica y justinianea.

La hereditas aparece como un concepto propio del ius civile regulado por las XII Tablas, las leyes de la República y la interpretatio de los juristas. La bonorum possessio surge en el ius honorarium y distingue cum re y sine re; secundum tabulas, contra tabulas y sine tabulas. En cuanto a los principios de derecho sucesorio romano: a) principio de la universalidad de la herencia, del que resultan: principio de responsabilidad ultra vires hereditatis, incompatibilidad de la sucesión testada y la sucesión intestada, imposibilidad de instituir heredero en cosa cierta y determinada y consustancialidad entre testamento e institución de heredero; b) primacía de la sucesión testada sobre la intestada ya desde las XII Tablas.

Analiza los presupuesto de la sucesión hereditaria, comenzando con la delación, es decir, el llamamiento hecho a una o varias personas para adquirir la herencia, y la adquisición de la herencia mediante la aceptación. Sigue la herencia yacente, esto es, el tiempo transcurrido desde la delación hasta la aceptación de la herencia.

Producida la adquisición de la herencia, el heredero se coloca en la misma posición jurídica del causante. El patrimonio hereditario se mezcla con el patrimonio propio del heredero formando una sola masa. Se transmiten así bienes, créditos y deudas confundiéndose con las del propio heredero. Así, se extinguen los créditos y deudas que existían recíprocamente entre causante y heredero, lo que da lugar a una responsabilidad ultra vires hereditatis. El Derecho Romano 
establece a favor de los acreedores de la herencia: la satisdatio suspecti tutoris y la separatio bonorum.

Aborda la sucesión testamentaria, comenzando con una clara exposición del concepto de testamento como negocio jurídico regulado por el ius civile, de carácter formal unilateral, y mortis causa, personalísimo y revocable, por el que una persona instituye uno o varios herederos. Sigue la capacidad para otorgar testamento, reservado a los ciudadanos romanos que estén en posesión del triple status: libertatis, civitatis y familiae. La capacidad para testar se exige tanto en el momento de hacer testamento, como al tiempo de la muerte, además debe mantenerse ininterrumpidamente durante todo este tiempo. La capacidad para suceder también está reservada a los ciudadanos romanos, por influencia del cristianismo se ampliaran los sujetos destinatarios de los testamentos. Distinto son los indignos, éstos tienen capacidad para suceder y pueden aceptar la herencia pero el fisco les priva de lo adquirido por considerarlos indignos.

El testamento debía redactarse conforme a una determinada estructura, de acuerdo con la praxis notarial romana: nombre del testador, institución de heredero, desheredación, sustituciones (vulgar, pupilar, cuasipupilar), legados, fideicomisos, nombramiento de tutores, nombramiento de administradores, lugar, fecha, sellos del testador y de los testigos. Las formas del testamento evolucionan según las épocas: a) época arcaica, testamento calatis comitis, testamento in procintu, testamento per aes et libram; b) época postclásica, testamento civil per aes et libram y testamento pretorio; c) época justinianea, testamento privado (oral o escrito), testamentos públicos (testamentum principi oblatum, testamentum apud acta o testamento judicial, testamento ológrafo). Los testamentos especiales son: testamento militar, testamento del ciego, testamento del analfabeto, testamento ruri conditum, testamentum pestis temporis, testamentum parentum inter liberos y testamento realizado a favor de la Iglesia y de las piae causae.

Sigue el análisis del codicilo, depósito y apertura del testamento, la institución de heredero (derecho de acrecer y partición), la collatio bonorum (collatio emancipati, collatio dotis y colación de los descendientes), las sustituciones (vulgar, pupilar y quasi pupilar), legados (legatum per vindicationem, legatum per damnationem, legado sinendi modo, legatum per praeceptionem), fideicomisos, interpretación, ineficacia y revocación del testamento y, por último, la sucesión intestada. Se cierra la obra con un pedagógico y amplio glosario de términos latinos de las Unidades didácticas y un Índice sistemático. 
Podemos concluir, con satisfacción, que estamos ante un excelente manual que reúne claridad expositiva y rigor científico, al propio tiempo que se configura como una obra que traspasa el ámbito docente, por el notable interés que presenta para los estudiosos del Derecho Romano, por las nuevas líneas de argumentación planteadas y la novedosa metodología empleada. 